\title{
1 Similar hibernation physiology in bats across 2 broad geographic ranges
}

3

Liam P McGuire ${ }^{1,2^{*}}$ Nathan W Fuller ${ }^{2,3}$, Yvonne A Dzal ${ }^{4}$, Catherine G Haase ${ }^{5,6}$, Kirk A Silas ${ }^{7}$, Craig KR Willis ${ }^{4}$, Sarah H Olson ${ }^{7}$, and Cori L Lausen ${ }^{8}$

1. Department of Biology, University of Waterloo, 200 University Ave W, Waterloo, ON, Canada N2L 3G1

2. Department of Biological Sciences, Texas Tech University, 2901 Main St, Lubbock, TX, USA 79409

3. Current Address: Nongame and Rare Species Program, Texas Parks and Wildlife, Austin, TX, USA 78744

4. Department of Biology, University of Winnipeg, 515 Portage Ave, Winnipeg, MB, Canada R3B 2E9

5. Department of Microbiology and Immunology, Montana State University, PO Box 173520, Bozeman, MT, USA 59717

6. Current Address: Department of Biology, Austin Peay State University, PO Box 4718, Clarkesville, TN, USA 37040

7. Wildlife Conservation Society, Health Program, Bronx, NY, USA

8. Wildlife Conservation Society Canada, Western Canada Bat Program, PO Box 606, Kaslo, BC Canada VOG $1 \mathrm{MO}$

${ }^{*}$ Corresponding Author: Liam P McGuire Department of Biology University of Waterloo 200 University Ave W, Waterloo, ON, Canada N2L 3G1

E: liam.mcguire@uwaterloo.ca P: 519-888-4567 ext 35995

Short Title: Intraspecific variation in hibernation physiology

Word Count: 4,848 words (Abstract through Discussion)

Acknowledgements: We appreciate all colleagues on our team that contributed to ongoing discussion of the ideas and related aspects of the research we present here, including Meredith McClure, David Hayman, Reed Hranac, Raina Plowright, Brett Dickson, Emily Johnson, and Emma Kunkel. Field research spanning 9 sites in 8 states/provinces and 2 countries is a daunting challenge, and would not have been possible without assistance provided by a long list of individuals that provided crucial support with logistic coordination, and fieldwork and permitting support. We are grateful to all those that supported our research, including Lindsay Anderson, Dan Bachen, Charlene Barker, David Bishop, Fauve Blanchard, Dave Bobbit, German Botto, Ellen Brandell, Adam Brewerton, Joanna Burgar, Connie Campbell, Muriel Chahine, Dave Critchley, Jurgen Deagle, Kevin Downing, Orville Dyer, Troy Ellsworth, Heather Fenton, Steve Fox, Heather Gates, Danika Gerylo, Purnima Govindarajulu, Imogen Grant-Smith, Konstantin von Gunten, Marie-Helene Hamel, Lauri Hanauska-Brown, Jason Headley, Dave Hobson, Danica Hogan, Greg Horne, Anna Magdalena Hubmann, Sharon Irwin, Tina Jackson, Devin Jones, Kellen Keisling, Allicia Kelly, Mike Kelly, Paul Knaga, Eli Lee, Erin Low, Kelsey Low, Brandon Mackinnon, Bryce Maxell, Ryan McKay, Katie McNab, Dan Neubaum, Cory Olson, Felix Ossig-Bonanno, Lori Parker, Cochise Paulette, Vladimir 
44 Paulik, Evan Phillips, Chuck Priestley, Jason Rae, John Roth, Maria-Camila Roy-Avilan, Frank Schlichting, 45 Jenna Schulhof, Helen Schwantje, Todd Shury, Lisa Sims, Geoff Skinner, Erin Tattersal, Dylan Taylor, Nina

46 Veselka, Lisa Wilkinson, Jason Williams, Joanna Wilson, Masako Wright, Ivan Yates, and Vladimir

47 Zumorin.

\section{Abbreviations}

$50 \mathrm{TMR}$ (torpid metabolic rate), EWL (evaporative water loss), WVP (water vapor pressure), $\dot{V} \mathrm{CO}_{2}$ (rate of 51 carbon dioxide production)

\section{Declarations}

54 Funding-This project was funded in part with Federal funds from the Department of Defense Strategic 55 Environmental Research and Development Program, under Contract Number W912HQ-16-C-0015. Any 56 opinions, findings, and conclusions or recommendations expressed in this publication are those of the

57 authors and do not necessarily reflect the views of the United States government. Additional funding 58 was provided by the United States Fish and Wildlife Service (CFDA program 15.657 grant F17AP00593), 59 Texas Tech University, and the Alberta Conservation Association.

61 interests.

63 Tech University Institutional Animal Care and Use Committee (protocol 16031-05). All procedures conducted in Canada conformed to the guidelines of the Canadian Council on Animal Care and were permitted by Alberta Environment and Parks (17-214 and 18-016), British Columbia Ministry of Forest 
69 Permits for fieldwork in the United States were obtained from the Montana Department of Fish, Wildlife

70 \& Parks (2016-104, 2017-018, and 2018-008), Colorado Parks and Wildlife (16TR2172, 17TR2172,

71 18TR2172, and 19TR2172), Nevada Department of Wildlife (497636), Utah Division of Wildlife Resources

72 (2COLL10094), National Park Service (ORCA-2018-SCI-0001).

73 Availability of Data and Material- Data will be submitted to Dryad Data Repository prior to publication.

74 Author Contributions- LPM, SHO, CLL conceived the study. LPM, SHO, CLL, and CKRW secured funding.

$75 \mathrm{NWF}, \mathrm{CGH}, \mathrm{KAS}, \mathrm{YAD}$, collected data. LPM analyzed the data and drafted the manuscript. All authors

76 contributed editorial comments on the manuscript. 


\section{Abstract}

78 Species with broad geographic ranges may experience varied environmental conditions throughout their

79 range leading to local adaptation. Variation among populations reflects potential adaptability or

80 plasticity, with implications for populations impacted by disease, climate change, and other

81 anthropogenic influences. However, behaviour may counteract divergent selection among populations.

82 We studied intraspecific variation in hibernation physiology of Myotis lucifugus (little brown myotis) and

83 Corynorhinus townsendii (Townsend's big-eared bat), two species of bats with large geographic ranges.

84 We studied M. lucifugus at three hibernacula which spanned a latitudinal gradient of $1,500 \mathrm{~km}$, and $C$.

85 townsendii from 6 hibernacula spread across 1,200 km latitude and 1,200 km longitude. We found no

86 difference in torpid metabolic rate among populations of either species, nor was there a difference in

87 the effect of ambient temperature among sites. Evaporative water loss was similar among populations

88 of both species, with the exception of one $C$. townsendii pairwise site difference and one $M$. lucifugus

89 site that differed from the others. We suggest the general lack of geographic variation is a consequence

90 of behavioural microhabitat selection. As volant animals, bats can travel relatively long distances in

91 search of preferred microclimates for hibernation. Despite dramatic macroclimate differences among

92 populations, hibernating bats are able to find preferred microclimate conditions within their range,

93 resulting in similar selection pressures among populations spread across wide geographic ranges.

94 Keywords: Hibernation, torpid metabolic rate, evaporative water loss, local adaptation, Myotis

95 lucifugus, Corynorhinus townsendii 
97 Studies seeking to understand broad scale ecological and evolutionary processes often consider variation in phenotypic traits among geographically isolated populations (Garland Jr and Adolph 1991;

99 Kawecki and Ebert 2004). Organisms with broad geographic ranges may have to contend with dramatic 100 differences in climate and environmental conditions throughout their range and, thus, exhibit different 101 strategies to cope with this climatic and environmental variability. Some species may adopt a generalist 102 strategy, but specialist-generalist tradeoffs suggest there may be selection for alternate strategies 103 (Kawecki and Ebert 2004). Species with large geographic ranges may instead specialize on a relatively 104 narrow range of environmental conditions (e.g., microclimate specialists), or may migrate long distances 105 seasonally to remain in favorable conditions year-round. Among more sedentary species, intraspecific 106 variation may result from phenotypic plasticity, where different phenotypes arise without underlying 107 genetic change, especially in highly variable environments. Alternatively, populations of widespread 108 species may adapt to local conditions that may be relatively consistent among years, but vary 109 dramatically across the species range. Although clearly an important topic, many studies do not consider intraspecific variation (or

111 implicitly assume that local adaptation is not a major factor) due to the financial and logistic challenges 112 associated with collecting data from multiple widespread populations. However, intraspecific variation 113 has great evolutionary significance (Gould and Johnston 1972). Varying environments impose different 114 selection pressures among populations, selecting for traits linked to increased fitness in these 115 environments. Challenges posed by the environment can constrain the distribution of the species (e.g., 116 Humphries et al. 2002), and populations that occur at range margins may be more likely to be locally 117 adapted, as local conditions may otherwise prevent the occurrence of the species. Ultimately, resulting 118 differences among populations reflect potential adaptability of the species with broad implications 
ranging from coping with climate change and other anthropogenic influences to speciation (Doebeli and

120 Dieckmann 2003; Otto 2018).

From an energetic perspective, local adaptations and specialization will be most pronounced

122 under situations of extreme energetic challenges. For many temperate species, the limitation of food

123 availability and increased thermoregulatory demands of winter represent a combined energetic

124 challenge. Hibernating bats are an excellent study system to address questions of local adaptation in

125 broadly distributed populations. Many species of bats have very broad geographic distributions, often

126 with ranges that cover large parts of entire continents. Therefore, populations of these widely

127 distributed species will experience a wide range of environmental conditions due to latitudinal

128 gradients, the influence of mountain ranges, or the influence of large bodies of water, in some cases

129 resulting in populations persisting in different biomes. Bats are also interesting to consider as they are

130 highly mobile species. Some species of bats migrate latitudinally to seek out favorable conditions year-

131 round, but many more species instead migrate relatively short distances $(<500 \mathrm{~km})$ to seek out

132 appropriate habitat for winter hibernation (Fleming and Eby 2003). For those species that do not

133 overwinter at great distances from their summer breeding grounds, winter poses an extreme energetic

134 challenge. Indeed, hibernation represents the highest period of mortality for many species (Davis 1966;

135 Frick et al. 2010; Lentini et al. 2015). Many species of bats are comprised of populations that hibernate

136 across broad geographic ranges, but little is known about how hibernation energetics vary among

137 populations, or the extent to which local adaptation results in regional phenotypic variation.

The objective of our study was to understand how hibernation physiology varies among

141 environmental conditions across populations could affect hibernation strategies. We made two

142 alternate predictions. If widely distributed species are locally adapted to regional environmental 
143 conditions, we predicted we would observe physiological differences among bats from different sites.

144 Alternatively, if populations from throughout the species range seek out and select similar hibernacula 145 then we predicted we would not observe differences across our study sites.

146 Materials and Methods

147 Study Species and Study Sites-We included two species of hibernating bats in our study. Corynorhinus 148 townsendii (Townsend's big-eared bat) is a small (approximately $5-13 \mathrm{~g}$ body mass) insectivorous bat 149 (family Vespertilionidae). The distribution of $C$. townsendii spans across western North America, 150 extending south into Mexico and north into southern British Columbia (Kunz and Martin 1982). Two 151 isolated subspecies occur in the eastern United States (C. townsendii virginianus and C. t. ingens) but we 152 did not consider these subspecies in our study. C. townsendii often hibernates in caves and mines, but is 153 generally thought to select colder, drier, and more variable sites for hibernation than many other 154 species (Kunz and Martin 1982). Populations may migrate short distances from maternity colonies to 155 hibernacula, but $C$. townsendii sometimes uses caves or mines as maternity roosts and may even use 156 separate areas of one cave for maternity roosting and hibernation (Sherwin et al. 2000). Despite its 157 widespread distribution, $C$. townsendii hibernation has received comparatively (compare with $M$. 158 lucifugus, below) little study (e.g., Hughes 1968; Humphrey and Kunz 1976; Sherwin et al. 2000; Ingersoll 159 et al. 2010). Myotis lucifugus (little brown myotis) is also a small (approximately $6-12 \mathrm{~g}$ body mass) 161 insectivorous bat (family Vespertilionidae) and has one of the largest geographic distributions among 162 North American bats. The species regularly occurs from Georgia in the southeast to Alaska in the northwest (Fenton and Barclay 1980). There has been extensive study of hibernation in M. lucifugus, 164 though primarily focused in the northeast (e.g., Fenton 1969; Thomas et al. 1990; Thomas and Cloutier 165 1992a; Kunz et al. 1998; McGuire et al. 2009) and Manitoba (e.g., Jonasson and Willis 2012; Czenze et al. 
2013; Norquay and Willis 2014; McGuire et al. 2017). Myotis lucifugus may travel several hundred

167 kilometers from summer maternity roosts to winter hibernacula (Fenton 1969; Norquay et al. 2013).

168 Hibernacula are typically caves or mines with stable, cool temperatures, and consistently high humidity

169 (Fenton and Barclay 1980).

We collected physiological measurements from free-living $C$. townsendii at hibernacula over a

171 region that spanned $1,200 \mathrm{~km}$ north to south, and 1,200 $\mathrm{km}$ from east to west, including one of the

172 northernmost hibernacula known for the species (Figure 1). We conducted fieldwork at sites in

173 Colorado, Utah, Nevada, Oregon, and British Columbia. Similarly, we collected measurements from $M$.

174 lucifugus at hibernacula in Montana, Alberta, and Northwest Territories, including the most northerly

175 known hibernaculum for the species (Figure 1; Wilson et al. 2014). The M. lucifugus study sites

176 represented a latitudinal gradient of approximately $1,500 \mathrm{~km}$. None of our sites were affected by white-

177 nose syndrome (Willis 2015) at the time of our fieldwork.

We characterized the climate at each of our study sites based on $1981-2010$ climate normals

179 (Arguez et al. 2012; Environment and Climate Change Canada 2020). Although it was not our explicit aim

180 to test for variation along specific environmental gradients, the M. lucifugus sites spanned a wide

181 temperature gradient and C. townsendii sites included both arid sites and much more mesic sites (Table

182 1). Microclimates can be highly variable within sites (Perry 2013; McClure et al. 2020), and bats move

183 within sites during hibernation (Ransome 1968; Boyles et al. In review), therefore we did not attempt to

184 relate measured physiological variables (see below) to the conditions experienced within a site.

Data Collection- We captured bats at hibernacula during pre-hibernation swarming or during midwinter

over three field seasons from 2017 to 2019. Swarming bats were captured in mist-nets over several

187 days. In mid-winter we made a single entry into the hibernaculum to minimize disturbance (coordinating with planned surveys where possible) and captured bats by hand from the walls of the hibernaculum. 
We recorded body mass ( $\pm 0.1 \mathrm{~g}$; Ohaus Corporation USA), forearm length ( $\pm 0.1 \mathrm{~mm}$; Avinet Inc.) and sex. We excluded any bats that were suspected to be young of the year (Brunet-Rossinni and Wilkinson 2009) and make the assumption that all of the bats in our study were adults.

We selected a subset of up to 14 bats each night to be held for respirometry measurements, preferentially maintaining an even sex ratio and including the heaviest bats available to avoid additional stress to bats in relatively poor condition. We used open flow respirometry to measure torpid metabolic rate (TMR) and evaporative water loss (EWL) across a range of temperatures. At all American field sites respirometry measurements were performed on site in a mobile laboratory. Animal chambers ( $350 \mathrm{~mL}$ glass jars) had wire lattice as a roosting surface, mineral oil to the bottom of the chamber to prevent bat excretions from biasing water vapor pressure (WVP) measurements, and $0.2 \mu \mathrm{m}$ in-line filters (ColeParmer, \#15945-42) to prevent possible Pseudogymnoascus destructans contamination (the causative agent of white-nose syndrome). Chambers were housed inside a dark, temperature-controlled $\left( \pm 0.5^{\circ} \mathrm{C}\right)$ cabinet (PELT-5, Sable Systems International). We used calibrated thermocouple probes (TC-2000; Sable Systems International) hanging within each metabolic chamber to continuously monitor ambient temperature throughout experimental trials. Incurrent air was scrubbed with Drierite ${ }^{\circledR}$ (W.A. Hammond Drierite Co. LTD, Xenia, Ohio) to remove water vapor, soda lime (Sigma-Aldrich cat no: 72073) to remove $\mathrm{CO}_{2}$, and finally magnesium perchlorate (Sigma-Aldrich cat no: 222283 ) to remove additional water vapor released from the $\mathrm{CO}_{2}$ scrub. We settled bats at $10{ }^{\circ} \mathrm{C}$ for $12 \mathrm{~h}$ prior to the start of measurements, maintaining humidity ( $85 \%$ RH; DG-4 dew point generator, Sable Systems) during the settling phase. We maintained flow rate (flowbar FB-8; Sable Systems) at approximately $300 \mathrm{~mL} / \mathrm{min}$ during settling, and reduced flow rate to $100-120 \mathrm{~mL} / \mathrm{min}$ when bats entered torpor. We sequentially monitored each bat (RM-8 multiplexer, Sable Systems) at 10 min intervals. Following $12 \mathrm{~h}$ of settling, we switched to a stream of dry air to avoid potential condensation at the low saturated WVP associated with low temperatures. We cycled through bats and the baseline reference channel at 3 min intervals 
213 (accounting for washout period) during the measurement phase, starting at $10^{\circ} \mathrm{C}$ and sequentially

214 reducing temperature to 8,5 , and $2{ }^{\circ} \mathrm{C}$. Each temperature treatment was maintained for approximately

$2153 \mathrm{~h}$, corresponding to $7-8$ measurements of TMR and EWL per bat at each temperature. Excurrent air

216 was subsampled at $75 \mathrm{~mL} / \mathrm{min}$ for measurement of WVP and excurrent $\mathrm{CO}_{2}$ (Field Metabolic System;

217 Sable Systems International). Respirometry gas analyzers were regularly calibrated with custom certified 218 span gas (AirGas Cuevas Distribution Inc, USA or Praxair Canada Inc.).

Respirometry procedures in Canada followed the same general protocol, with some minor

220 differences. Rather than conducting measurements on site in a mobile lab, bats in Canada were

221 transported $<50 \mathrm{~km}$ to a local field station (approximately 30 minutes, bats held in individual cloth bags

222 during transport). Animal chambers were of similar design but $250 \mathrm{~mL}$ instead of $350 \mathrm{~mL}$, and chambers

223 were maintained in a dark custom temperature cabinet $\left( \pm 0.5^{\circ} \mathrm{C}\right.$; modified from 6 cubic foot mini-fridge,

224 Danby Products Ltd.). During the settling phase bats were provided ambient air that did not have a

225 precisely controlled WVP, but was $>85 \%$ RH to match measurements made at American sites. Instead of

226 an FB-8 flowbar, in Canada we used a subsampler (SS-4; Sable Systems International) and factory

227 calibrated flow controllers (MFC-2; Sable Systems International) to maintain flow at the same rates used

228 at American field sites. Instead of an FMS multi-analyzer system, in Canada we used separate analyzers

229 to measure WVP (RH-300; Sable Systems International) and $\mathrm{CO}_{2}$ (FoxBox Respiratory System; Sable

230 Systems International). We do not anticipate that any of differences in respirometry measurement

231 would impact measurements used in our analysis.

The total respirometry protocol took approximately $24 \mathrm{~h}$, during which time bats were

233 continuously monitored. If a bat showed signs of increasing metabolic rate (i.e., not in steady state

234 torpor) we increased flow rate for that bat until the bat returned to torpor. Bats that refused to settle

235 were removed from the experiment to prevent unnecessary stress and depletion of fat stores. Upon 
completion of measurements we offered water and either mealworms or a high calorie nutritional

237 supplement (Nutrical, Tomlyn Veterinary Science) to each bat before release at the site of capture.

We processed respirometry recordings in Expedata (v1.9.13; Sable Systems). We corrected for

lag and drift and then calculated $\dot{V} \mathrm{CO}_{2}$ using equation 10.5 from Lighton (2018) and evaporative water

240 loss using equation 10.9 from Lighton (2018). We converted $\dot{V} \mathrm{CO}_{2}$ to metabolic rate (in $\mathrm{mW}$ ) assuming

241 fat oxidation (respiratory quotient $=0.7$; Price and Mager 2020). We quality checked all measurements

242 and excluded values from bats that were not torpid or if there was an erroneous measurement (values $<$

$2430.25 \mathrm{~mW} \mathrm{~g}^{-1}$ or $>2 \mathrm{~mW} \mathrm{~g}^{-1}$ ) and selected the minimum TMR measurement at each temperature for each

244 individual for further analyses. We report mass-specific metabolic rates $\left(\mathrm{mW} \mathrm{g}^{-1}\right)$ for ease of comparison

245 with other literature and other accompanying studies, but the qualitative outcomes were not affected

246 whether using mass-specific or whole animal measurements.

247 Data Analysis- We used linear mixed models to analyze TMR or EWL following procedures described by

248 Zuur et al. (2009), with separate models for C. townsendii and M. lucifugus. We suspected we might

249 observe greater variance in TMR or EWL at either the highest or lowest temperatures due to individual

250 physiological thresholds. Therefore, we included a variance structure in our analysis which allowed for a

251 heterogeneous variance among temperatures (varldent variance structure in nlme package of $R$

252 statistical software; Zuur et al. 2009; R Core Team 2020; Pinheiro et al. 2021). We included a random

253 effect of individual to account for repeated measures and tested for the main effects of temperature,

254 sex, season (pre-hibernation or mid-winter), site, and the interactions of temperature and site and

255 temperature and sex (in case bats from different sites or sexes responded differently to temperature).

256 We compared models with likelihood ratio tests, visually assessed residual plots, and used Tukey's post-

257 hoc tests for pairwise comparisons of significant effects. For all main effects we assessed statistical

258 significance at $\alpha=0.05$, but in post-hoc comparisons we considered pairwise differences if $p<0.10$. All 
statistical analysis was conducted in R (v 3.6.3; R Core Team 2020) including packages ggmap (Kahle and

260 Wickham 2013), dplyr (Wickham et al. 2021), lubridate (Grolemund and Wickham 2011), nlme (Pinheiro

261 et al. 2021), and multcomp (Hothorn et al. 2008).

262 Permits and Ethics- All field activities were conducted under permits from the respective state or

263 provincial agencies. Although none of our sites were affected by white-nose syndrome at the time we

264 conducted our fieldwork, we followed US Fish and Wildlife Service protocols for fieldwork and

265 decontamination (US Fish and Wildlife Service 2018). All field methods were approved by the

266 Institutional Animal Care and Use Committee at Texas Tech University (all sites in the United States), the

267 National Park Service (Oregon), Alberta Environment and Parks, British Columbia Ministry of Forest

268 Lands Natural Resource Operations and Rural Development, Northwest Territories Department of

269 Environment and Natural Resources, and Parks Canada.

$270 \quad$ Results

271 C. townsendii- Our analysis included data for 152 C. townsendii from 6 different sites (4 mines, 2 caves;

$272 \mathrm{n}=10-47$ bats per site). Our dataset included a similar sex ratio among sites (test for equality of

273 proportions; $\chi^{2}=10.0, d f=5, p=0.07$ ) with a female bias across sites (number females $\geq$ males at all

274 sites; binomial test $p=0.0001$ ). Models of torpid metabolic rate were better supported when they

275 included heterogeneous variance among temperatures (likelihood ratio $=32.38, d f=3, p<0.0001$ ) and

276 the random effect of individual (likelihood ratio $=100.92, \mathrm{df}=1, \mathrm{p}<0.0001$ ). Our dataset includes

277 samples from both pre-hibernation and mid-winter at four sites, and mid-winter only at two sites.

278 Torpid metabolic rate was related to temperature (likelihood ratio $=12.84, d f=3, p=0.005$ ) but the

279 effect of temperature did not vary among sites (site:temperature interaction, likelihood ratio $=22.30, \mathrm{df}$

$280=15, p=0.10$ ) or between sexes (sex:temperature interaction, likelihood ratio $=1.70, d f=3 p=0.64$ ).

281 Torpid metabolic rates measured in winter were slightly greater $\left(0.1 \pm 0.07 \mathrm{~mW} \mathrm{~g}^{-1}\right)$ than when 
measured during swarming (likelihood ratio $=4.85, \mathrm{df} 1, \mathrm{p}=0.03$ ), but given that no similar effect was observed for EWL and no seasonal effects were observed for M. lucifugus (below), this may be a spurious result. Torpid metabolic rate did not vary among sites (likelihood ratio $=6.85, \mathrm{df}=5, \mathrm{p}=0.23$ ) or between sexes (likelihood ratio $=0.15, \mathrm{df}=1, \mathrm{p}=0.70$ ). Torpid metabolic rate was greater at $2^{\circ} \mathrm{C}$ than either 5 or $8^{\circ} \mathrm{C}$ and TMR at $10^{\circ} \mathrm{C}$ was intermediate, suggesting decreasing TMR to a minimum metabolic rate $\left(0.33 \pm 0.03 \mathrm{~mW} \mathrm{~g}^{-1}\right)$ over the range of $5-8^{\circ} \mathrm{C}$ (Figure $2 \mathrm{a}$ ) and minimum defended temperature between 2 and $5^{\circ} \mathrm{C}$.

Trends for EWL generally followed those observed for TMR. For EWL, there was better support for models that included heterogeneous variance among temperatures (likelihood ratio $=107.10, \mathrm{df}=3$, $291 p<0.0001$ ) and the random effect of individual (likelihood ratio $=57.51, d f=1, p<0.0001$ ). Evaporative water loss varied across temperatures (likelihood ratio $=19.03, \mathrm{df}=3, \mathrm{p}=0.0003$ ) but the effect of temperature did not differ among sites (site:temperature interaction; likelihood ratio $=15.84, d f=15, p$

$294=0.39$ ) or between sexes (sex:temperature interaction; likelihood ratio $=4.49, \mathrm{df}=3, \mathrm{p}=0.21$ ).

295 Evaporative water loss did not differ between seasons (likelihood ratio $=2.60, d f=1, p=0.11$ ) or sexes

296 (likelihood ratio $=2.74, \mathrm{df}=1, \mathrm{p}=0.10)$. Minimum EWL $\left(0.010 \pm 0.0007 \mathrm{mg} \mathrm{H}_{2} \mathrm{O} \mathrm{min} \mathrm{m}^{-1} \mathrm{~g}^{-1}\right.$ ) was measured 297 at $5-8^{\circ} \mathrm{C}$ (Figure 2b), the same temperature range for minimum TMR. There was one pairwise 298 difference in EWL among sites (likelihood ratio $=13.05, \mathrm{df}=5, \mathrm{p}=0.02$ ), with lower EWL measured in 299 British Columbia compared to Colorado (Tukey's post-hoc $p=0.01$ ). There were no other differences 300 among sites.

M. lucifugus- Our analysis included data for 99 M. lucifugus from 3 different caves (sample size ranged 302 from $20-40$ bats per site). Our dataset included males and females at all sites, but sex ratio varied among sites (test for equality of proportions; $\chi^{2}=12.6, \mathrm{df}=2, \mathrm{p}=0.001$ ), with heavy male bias in 304 Montana and Northwest Territories (binomial test; $p<0.0001$ ) and an even sex ratio in Alberta 305 (binomial test: $p=0.87$ ). In Montana we conducted fieldwork during pre-hibernation swarming and mid- 
winter hibernation, but at the Alberta and Northwest Territories sites we only conducted pre-

307 hibernation fieldwork. In an analysis of just data from Montana, TMR did not differ between fall and winter (likelihood ratio $=0.83, \mathrm{df}=1, \mathrm{p}=0.36$ ). Therefore, we pooled swarming and hibernation data in Montana and did not include season in comparison among the three sites. As for the results of $C$. townsendii, there was better support for models that included a random effect of individual (likelihood ratio $=27.33, \mathrm{df}=1, \mathrm{p}<0.0001$ ) and allowed for differences in variance among temperatures (likelihood ratio $=22.17, \mathrm{df}=3, \mathrm{p}=0.0001$ ). Torpid metabolic rate varied among temperatures (likelihood ratio $=$ $15.21, d f=3, p=0.002$ ), but the effect of temperature did not vary among sites (site:temperature interaction; likelihood ratio $=7.06, \mathrm{df}=6, \mathrm{p}=0.32$ ) or between sexes (sex:temperature interaction; likelihood ratio $=6.04, \mathrm{df}=3, \mathrm{p}=0.11$ ). There were no differences in torpid metabolic rate among sites (likelihood ratio $=3.21, \mathrm{df}=2, \mathrm{p}=0.20$ ) or between sexes (likelihood ratio $=0.04, \mathrm{df}=1, \mathrm{p}=0.84$ ).

317 Torpid metabolic rate was greater at $10^{\circ} \mathrm{C}$ than at any of 8,5 , or $2^{\circ} \mathrm{C}$ (Figure 3a). Minimum metabolic rate was $0.30 \pm 0.02 \mathrm{~mW} \mathrm{~g}^{-1}$ and the absence of an increase in metabolic rate at the lower tested temperatures indicates the minimum defended temperature is $<2^{\circ} \mathrm{C}$, the coldest temperature we tested at.

Evaporative water loss models that included the random effect of individual and heterogeneous variance structure were better supported (likelihood ratio $=19.74, \mathrm{df}=1, \mathrm{p}<0.0001$; likelihood ratio $=$ $67.74, \mathrm{df}=3, \mathrm{p}<0.0001)$. There was a marginally significant interaction between site and temperature

324 (likelihood ratio $=12.96, \mathrm{df}=6, \mathrm{p}=0.044$ ) but upon inspection the interaction was driven only by slightly 325 greater EWL at the Alberta site at $8^{\circ} \mathrm{C}$ and did not indicate any broader patterns of variation among 326 temperatures or sites. After excluding the site by temperature interaction, EWL did not differ between 327 sexes (likelihood ratio $=1.95, \mathrm{df}=1, \mathrm{p}=0.16$ ) but was related to temperature (likelihood ratio $=19.75$, $328 \mathrm{df}=3, \mathrm{p}=0.0002$ ) with greater evaporative water loss at $10^{\circ} \mathrm{C}$ than either 8 or $5^{\circ} \mathrm{C}$ (Figure $3 \mathrm{~b}$ ). As for $\mathrm{C}$. 329 townsendii there was one site effect; bats from Montana had greater EWL than either of the other two 
sites (likelihood ratio $=13.81, \mathrm{df}=2, \mathrm{p}=0.001$; Figure $3 \mathrm{~b}$ ). Minimum EWL (calculated at 5 and $8{ }^{\circ} \mathrm{C}$

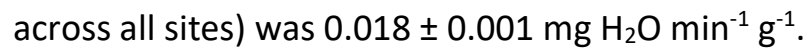

\section{Discussion}

Despite large geographic distances $(>1,000 \mathrm{~km}$ ) and climatic variation (Table 1) among our study sites, we found no evidence of intraspecific variation, or local adaptation, in TMR. Torpid metabolic rate did not vary among sites, nor did the relationship between TMR and ambient temperature. There are

337 few studies that have previously considered similar comparisons, with mixed results. In two studies

338 which contrasted bat populations across evaporative water loss gradients, there was little to no 339 variation in metabolic rate among populations (Klüg-Baerwald and Brigham 2017; Gearhart et al. 2020), 340 consistent with the findings in our study. Notably, Dunbar and Brigham (2010) found variation in torpid

341 metabolic rate among populations of hibernating Eptesicus fuscus (big brown bats). However, the

342 differences in metabolic rates among populations were only observed at the coldest and warmest

343 temperatures tested, both of which were outside the range of temperatures we considered in our study.

344 In the range of $5-10^{\circ} \mathrm{C}$, torpid metabolic rate did not vary among the populations considered by 345 Dunbar and Brigham (2010), similar to our findings. Our objective was to test hibernation physiology 346 over a range of biologically relevant temperatures that might be regularly experienced by hibernating 347 bats. We might have observed intraspecific variation if we included temperatures farther below the 348 minimum defended temperature. However, assuming preferred microclimates are available, hibernators 349 should select temperatures slightly above those that result in minimum metabolic rate (Boyles and 350 McKechnie 2010; Boyles et al. 2020), but note that additional factors affect hibernation strategies, 351 including sex (Jonasson and Willis 2011; Czenze et al. 2017) and body condition (Boyles et al. 2007). 
352 Therefore, we conclude that within the range of temperatures which are likely to be preferred during

353 hibernation, there is no evidence for intraspecific variation in TMR.

The conclusion for EWL was generally consistent with the finding for TMR, but notably there were site differences in water loss. Among $C$. townsendii the relationship between water loss and temperature was consistent across populations, except for one pairwise combination of sites (British

357 Columbia and Colorado) that differed in evaporative water loss (by $0.009 \pm 0.003 \mathrm{mg} \mathrm{H}_{2} \mathrm{O} \mathrm{min}^{-1} \mathrm{~g}^{-1}$ ).

358 Similarly, for M. lucifugus, evaporative water loss was greater in Montana than at the other sites (by

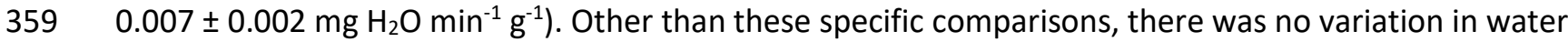
360 loss among sites for either species. It is notable that the only pairwise differences in EWL were observed 361 among the most distant sites: the British Columbia and Colorado sites for $C$. townsendii are separated by 362 approximately $1,400 \mathrm{~km}$, and the Montana M. lucifugus site is separated from the other two sites by 363 approximately 800 and 1,500 km respectively. High rates of gene flow among nearby populations 364 reduces phenotypic differentiation among populations, and differences may only become apparent at 365 greater distances (Rousset 1997). Considering biologically relevant conditions, the evidence for 366 intraspecific variation in EWL is even less compelling. We measured EWL in dry air, partially because of 367 methodological constraints (the challenge of maintaining humidity below saturation at low 368 temperatures) but also because measuring in dry air exacerbates potential differences in EWL among 369 groups (Klüg-Baerwald and Brigham 2017; McGuire et al. 2017). In natural arid conditions, free-living 370 animals would experience less water stress than in our measurement conditions, and the potential 371 differences among populations would be further diminished under real world conditions. Indeed, this 372 was exactly the finding in a study of hibernating E. fuscus that only observed a difference in EWL 373 between an arid and a mesic population when measured in dry air and not when measured under higher 374 humidity (Klüg-Baerwald and Brigham 2017). Taken together, the fact that differences were only 
observed among the most distant sites, and when measured under unnatural extreme conditions, we argue that there is likely to be little biologically relevant variation in EWL among free-living populations.

The potential for more pronounced differences in EWL (even if minimal) than TMR is consistent with previous studies (Klüg-Baerwald and Brigham 2017; Gearhart et al. 2020). Furthermore, variation in EWL but not TMR may reflect a physical difference among populations rather than a difference in a physiological process (Klüg-Baerwald and Brigham 2017). We measured total evaporative water loss, which is comprised of both respiratory and cutaneous water loss. Respiration is related to metabolic rate, and therefore differences in total evaporative water loss in the absence of differences in metabolic rate likely reflect differences in cutaneous water loss (Klüg-Baerwald and Brigham 2017; McGuire et al. 2017; Gearhart et al. 2020). Total water loss during torpor is thought to be primarily driven by cutaneous water loss (Thomas and Cloutier 1992b), due to low respiration rates and large surface area due to wing and tail membranes and large ears. Studies of hibernating bats often consider evaporative water loss as an important driver of hibernation energetics and success (Thomas and Geiser 1997; Willis et al. 2011; Ben-Hamo et al. 2013; Boratyński et al. 2015; Klüg-Baerwald and Brigham 2017; Haase et al. 2019) and this may be an important avenue for future studies considering intraspecific variation in hibernation physiology.

In general, we did not find strong evidence for local adaptation and intraspecific variation in hibernation physiology, despite studying two species with very large geographic ranges encompassing a wide gradient of environmental challenges. We suggest it is likely that rather than being locally adapted to different climate conditions, hibernating bats may be able to find suitable hibernacula with generally consistent microclimate across their range. Furthermore, some species mitigate environmental influences by clustering during hibernation (Boratyński et al. 2015). The combined effects of migration, microclimate selection, and clustering may represent an example of the Bogert effect, the phenomenon of behaviour reducing the effects of selection and therefore reducing local adaptation (Buckley et al. 
2015). This is particularly plausible for hibernating bats because of their ability to fly long distances in

400 search of suitable hibernacula (Griffin 1970). Furthermore, copulation occurs during pre-hibernation

401 swarming (Fenton 1969) and the long-distance movements to swarming sites and hibernacula result in

402 extensive gene flow among populations (Burns et al. 2014). Local adaptation typically requires restricted

403 gene flow (Kawecki and Ebert 2004) and therefore the combination of seasonal movement patterns and

404 behavioural thermoregulation (selecting preferred hibernation conditions, clustering) may contribute to

405 a lack of local adaptation in hibernation physiology. Behavior may be more important than physiology

406 and bats may be able to behaviorally select suitable hibernacula rather than physiologically specializing

407 on locally variable conditions during hibernation.

Our data suggests that within preferred microclimate conditions, there is little evidence of

intraspecific variation in hibernation physiology. However, it is important not to extrapolate this finding.

410 Extreme populations, hibernation strategy, global climate change, and disease may all affect

411 hibernation. As environmental conditions extend beyond the range of preferred conditions (e.g., at

412 range margins; Humphries et al. 2002), differences among widespread populations may become

413 apparent. We included populations of both species at their northern limits but it is possible that there

414 are more extreme unknown populations which are forced to hibernate outside their preferred range of

415 conditions. Furthermore, subterranean hibernacula are buffered from surface conditions (Perry 2013)

416 but some species select hibernacula that are more exposed to surface weather (Dunbar and Brigham

417 2010; Perry et al. 2010) and therefore may experience stronger gradients of environmental conditions.

418 Finally, there may be future changes in both extrinsic environmental conditions (global climate change)

419 and intrinsic hibernator phenotypes (e.g., disease consquences of white-nose syndrome; Auteri and

420 Knowles 2020).

Overall, we conclude that there is a general lack of intraspecific variation in hibernation

422 physiology among widespread bat populations across broad environmental gradients when measured 
423 within the range of environmental conditions likely to be selected during hibernation. We suggest that

424 highly mobile bats are able to seek out preferred microclimates for hibernation, regardless of local

425 macroclimate conditions, emphasizing the importance of both behavior and physiology when studying

426 how animals are adapted to their environments. However, there are multiple plausible scenarios (more

427 extreme environmental gradients, populations closer to the extremes of the range margin, global

428 climate change, disease consequences) which may reveal intraspecific variation in hibernation

429 physiology. Variations in phenotype and genotype among populations provide the potential for natural

430 selection. Such variation among populations may be important for speciation processes, adaptation to

431 changing climates, or source material for evolutionary rescue from zoonotic disease. 
433

Table 1. We collected measurements from Corynorhinus townsendii at 6 sites and from Myotis lucifugus at 3 sites. Sites for M. Iucifugus had a notable temperature gradient, while precipitation varied widely among sites for $C$. townsendii. Among $C$. townsendii sites, the most mesic site received approximately 6.5 times more precipitation than the most arid site. Among $M$. lucifugus sites, temperature decreased with latitude and the mean annual temperature at the most northern site was below freezing. All climate data from $1981-2010$ climate normals. Hibernation duration estimates are calculated from Hranac et al. (Accepted). We do not report precise locations of these sensitive sites, but general locations are illustrated in Figure 1.

\begin{tabular}{cccccc} 
Site & Annual & Mean Annual & Coldest & Warmest & Predicted Hibernation \\
& Precipitation $(\mathrm{mm})$ & ${\operatorname{Temperature~}\left({ }^{\circ} \mathrm{C}\right)}^{\operatorname{Month}^{1}\left({ }^{\circ} \mathrm{C}\right)}$ & $\operatorname{Month}^{2}\left({ }^{\circ} \mathrm{C}\right)$ & Duration $($ days $)$ \\
\hline
\end{tabular}

Corynorhinus townsendii sites

$\begin{array}{lc}\text { Nevada }^{3} & 248 \\ \text { Colorado } & 338 \\ \text { Utah } & 501 \\ \text { British Columbia } & 535 \\ \text { Oregon } & 1597\end{array}$

338

535

1597

Montana

Alberta

Northwest Territories
1. Mean of daily minimum temperature for the coldest month of the year, based on $1981-2010$ climate normals

2. Mean of daily maximum temperature for the warmest month of the year, based on $1981-2010$ climate normals.

3. The two sites in Nevada were in relatively close proximity and are characterized by a single weather station.

-11.7
-9.5
-8.4
-7.2
0.6

-9.7
-11.7
-27

normals
e normals.
tion.

30.9

33.9

120

89

127

139

28.7

34.6

81

27.5

22.7

23.3

154

170

205 
443

444

445

446

447

448

449

450

451

452

453

454

455

456

457

458

459

460

461

462

463

464

465

466

467

468

469

470

471

472

473

474

475

476

477

478

479

480

481

482

483

484

485

486
Arguez A, Durre I, Applequist S, Vose RS, Squires MF, Yin X, Heim Jr RR, Owen TW (2012) NOAA's 19812010 US climate normals: an overview. Bulletin of the American Meteorological Society 93 (11):1687-1697

Auteri GG, Knowles LL (2020) Decimated little brown bats show potential for adaptive change. Scientific reports $10(1): 1-10$

Ben-Hamo M, Muñoz-Garcia A, Williams JB, Korine C, Pinshow B (2013) Waking to drink: rates of evaporative water loss determine arousal frequency in hibernating bats. Journal of Experimental Biology 216 (4):573-577

Boratyński JS, Willis CK, Jefimow M, Wojciechowski MS (2015) Huddling reduces evaporative water loss in torpid Natterer's bats, Myotis nattereri. Comparative Biochemistry and Physiology Part A: Molecular \& Integrative Physiology 179:125-132

Boyles JG, Dunbar MB, Storm JJ, Brack V, Jr. (2007) Energy availability influences microclimate selection of hibernating bats. The Journal of experimental biology 210 (Pt 24):4345-4350. doi:10.1242/jeb.007294

Boyles JG, Johnson EM, Fuller NW, Silas KA, Hou L, Frick WF, McGuire LP (In review) An experimental assessment of behavioral microclimate selection and acclimation to hibernation conditions in a hibernating bat. Physiological and Biochemical Zoology

Boyles JG, Johnson JS, Blomberg A, Lilley TM (2020) Optimal hibernation theory. Mammal Review 50 (1):91-100

Boyles JG, McKechnie AE (2010) Energy conservation in hibernating endotherms: Why "suboptimal" temperatures are optimal. Ecological Modelling 221 (12):1644-1647

Brunet-Rossinni AK, Wilkinson GS (2009) Methods for age estimation and the study of senescence in bats. In: Kunz TH, Parsons S (eds) Ecological and Behavioral Methods for the Study of Bats. 2nd edn. Johns Hopkins University Press, pp 315-325

Buckley LB, Ehrenberger JC, Angilletta Jr MJ (2015) Thermoregulatory behaviour limits local adaptation of thermal niches and confers sensitivity to climate change. Functional Ecology 29 (8):1038-1047

Burns LE, Frasier TR, Broders HG (2014) Genetic connectivity among swarming sites in the wide ranging and recently declining little brown bat (M yotis lucifugus). Ecology and evolution 4 (21):41304149

Czenze ZJ, Jonasson KA, Willis CK (2017) Thrifty females, frisky males: winter energetics of hibernating bats from a cold climate. Physiological and Biochemical Zoology 90 (4):502-511

Czenze ZJ, Park AD, Willis CK (2013) Staying cold through dinner: cold-climate bats rewarm with conspecifics but not sunset during hibernation. J Comp Physiol B 183 (6):859-866. doi:10.1007/s00360-013-0753-4

Davis WH (1966) Population dynamics of the bat Pipistrellus subflavus. Journal of Mammalogy 47 (3):383-396

Doebeli M, Dieckmann U (2003) Speciation along environmental gradients. Nature 421 (6920):259-264

Dunbar MB, Brigham RM (2010) Thermoregulatory variation among populations of bats along a latitudinal gradient. J Comp Physiol B 180 (6):885-893

Fenton MB (1969) Summer activity of Myotis lucifugus (Chiroptera: Vespertilionidae) at hibernacula in Ontario and Quebec. Canadian Journal of Zoology 47 (4):597-602

Fenton MB, Barclay RMR (1980) Myotis lucifugus. Mammalian species (142):1-8

Fleming TH, Eby P (2003) Ecology of Bat Migration. In: Kunz TH, Fenton MB (eds) Bat Ecology. University of Chicago Press, Chicago, Illinois, pp 156 - 208 
Frick WF, Reynolds DS, Kunz TH (2010) Influence of climate and reproductive timing on demography of little brown myotis Myotis lucifugus. Journal of animal ecology 79 (1):128-136

Garland Jr T, Adolph SC (1991) Physiological differentiation of vertebrate populations. Annual Review of Ecology and Systematics $22(1): 193-228$

Gearhart C, Adams AM, Pinshow B, Korine C (2020) Evaporative water loss in Kuhl's pipistrelles declines along an environmental gradient, from mesic to hyperarid. Comparative Biochemistry and Physiology Part A: Molecular \& Integrative Physiology 240:110587

Gould SJ, Johnston RF (1972) Geographic variation. Annual Review of Ecology and Systematics 3 (1):457498

Griffin DR (1970) Migrations and homing of bats. In: Wimsatt WA (ed) Biology of Bats, vol 1. Academic Press, New York, pp 233 - 264

Grolemund G, Wickham H (2011) Dates and times made easy with lubridate. Journal of statistical software 40 (3):1-25

Haase CG, Fuller NW, Hranac CR, Hayman DT, McGuire LP, Norquay KJ, Silas KA, Willis CK, Plowright RK, Olson SH (2019) Incorporating evaporative water loss into bioenergetic models of hibernation to test for relative influence of host and pathogen traits on white-nose syndrome. PloS one 14 (10):e0222311

Hothorn T, Bretz F, Westfall P (2008) Simultaneous inference in general parametric models. Biometrical Journal: Journal of Mathematical Methods in Biosciences 50 (3):346-363

Hranac CR, Haase CG, McClure MM, Lausen CL, McGuire LP, Fuller NW, Marshall JC, Olson SH, Hayman DT (Accepted) What is winter? Modelling spatial variation in bat host traits and hibernation and their implications for overwintering energetics. Ecology and Evolution ECE-2021-01-00061.R1

Hughes SE (1968) Temperature of the bat, Plecotus townsendii, during arousal. Journal of Mammalogy 49 (1):140-142

Humphrey SR, Kunz TH (1976) Ecology of a Pleistocene Relict, the Western Big-Eared Rat (Plecotus townsendii), in the Southern Great Plains. Journal of Mammalogy 57 (3):470-494

Humphries MM, Thomas DW, Speakman JR (2002) Climate-mediated energetic constraints on the distribution of hibernating mammals. Nature 418 (6895):313-316

Ingersoll TE, Navo KW, de Valpine P (2010) Microclimate preferences during swarming and hibernation in the Townsend's big-eared bat, Corynorhinus townsendii. Journal of Mammalogy 91 (5):12421250

Jonasson KA, Willis CK (2011) Changes in body condition of hibernating bats support the thrifty female hypothesis and predict consequences for populations with white-nose syndrome. PloS one 6 (6):e21061

Jonasson KA, Willis CK (2012) Hibernation energetics of free-ranging little brown bats. The Journal of experimental biology 215 (Pt 12):2141-2149. doi:10.1242/jeb.066514

Kahle D, Wickham H (2013) ggmap: Spatial Visualization with ggplot2. The R journal 5 (1):144-161

Kawecki TJ, Ebert D (2004) Conceptual issues in local adaptation. Ecology letters 7 (12):1225-1241

Klüg-Baerwald BJ, Brigham RM (2017) Hung out to dry? Intraspecific variation in water loss in a hibernating bat. Oecologia 183 (4):977-985

Kunz TH, Martin RA (1982) Plecotus townsendii. Mammalian species (175):1-6

Kunz TH, Wrazen JA, Burnett CD (1998) Changes in body mass and fat reserves in pre-hibernating little brown bats (Myotis lucifugus). Ecoscience 5 (1):8-17

Lentini PE, Bird TJ, Griffiths SR, Godinho LN, Wintle BA (2015) A global synthesis of survival estimates for microbats. Biol Lett 11 (8):20150371

Lighton JR (2018) Measuring metabolic rates: a manual for scientists. Oxford University Press, 
McClure ML, Crowley D, Haase CG, McGuire LP, Fuller NW, Hayman DT, Lausen CL, Plowright RK, Dickson BG, Olson SH (2020) Linking surface and subterranean climate: implications for the study of hibernating bats and other cave dwellers. Ecosphere 11 (10):e03274

McGuire LP, Fenton MB, Guglielmo CG (2009) Effect of age on energy storage during prehibernation swarming in little brown bats (Myotis lucifugus). Canadian Journal of Zoology 87 (6):515-519. doi:10.1139/z09-041

McGuire LP, Mayberry HW, Willis CK (2017) White-nose syndrome increases torpid metabolic rate and evaporative water loss in hibernating bats. American Journal of Physiology-Regulatory, Integrative and Comparative Physiology 313 (6):R680-R686

Norquay KJ, Martinez-Nuñez F, Dubois JE, Monson KM, Willis CK (2013) Long-distance movements of little brown bats (Myotis lucifugus). Journal of Mammalogy 94 (2):506-515

Norquay KJO, Willis CKR (2014) Hibernation phenology of Myotis lucifugus. Journal of Zoology 294 (2):85-92. doi:10.1111/jzo.12155

Otto SP (2018) Adaptation, speciation and extinction in the Anthropocene. Proceedings of the Royal Society B 285 (1891):20182047

Perry RW (2013) A review of factors affecting cave climates for hibernating bats in temperate North America. Environmental Reviews 21 (1):28-39. doi:10.1139/er-2012-0042

Perry RW, Saugey DA, Crump BG (2010) Winter roosting ecology of silver-haired bats in an Arkansas forest. Southeastern Naturalist 9 (3):563-572

Pinheiro J, Bates D, DebRoy S, Sarkar D, Team RC (2021) nlme: Linear and nonlinear mixed effects models. R Package Version 3.1-152. edn.,

Price ER, Mager EM (2020) Respiratory quotient: Effects of fatty acid composition. Journal of Experimental Zoology Part A: Ecological and Integrative Physiology 333 (9):613-618

R Core Team (2020) R: A language and environment for statistical computing. R Foundation for Statistical Computing, Vienna, Austria

Ransome R (1968) The distribution of the Greater horse-shoe bat, Rhinolophus ferrum-equinum, during hibernation, in relation to environmental factors. Journal of Zoology 154 (1):77-112

Rousset $F$ (1997) Genetic differentiation and estimation of gene flow from F-statistics under isolation by distance. Genetics 145 (4):1219-1228

Sherwin RE, Stricklan D, Rogers DS (2000) Roosting affinities of Townsend's big-eared bat (Corynorhinus townsendii) in northern Utah. Journal of mammalogy 81 (4):939-947

Thomas D, Geiser F (1997) Periodic arousals in hibernating mammals: is evaporative water loss involved? Functional Ecology 11 (5):585-591

Thomas DW, Cloutier D (1992a) Evaporative water loss by hibernating little brown bats, Myotis lucifugus. Physiological Zoology 65 (2):443-456

Thomas DW, Cloutier D (1992b) Evaporative water loss by hibernating little brown bats, Myotis lucifugus. Physiological Zoology:443-456

Thomas DW, Dorais M, Bergeron J-M (1990) Winter energy budgets and cost of arousals for hibernating little brown bats, Myotis lucifugus. Journal of Mammalogy 71 (3):475-479

US Fish and Wildlife Service (2018) National White-Nose Syndrome Decontamination Protocol.

Wickham H, François R, Henry L, Müller K (2021) dplyr: A grammar of data manipulation. R Package Version 1.0.5 edn.,

Willis CK (2015) Conservation physiology and conservation pathogens: white-nose syndrome and integrative biology for host-pathogen systems. Integr Comp Biol 55 (4):631-641

Willis CKR, Menzies AK, Boyles JG, Wojciechowski MS (2011) Evaporative water loss is a plausible explanation for mortality of bats from white-nose syndrome. Integr Comp Biol 51 (3):364-373. doi:10.1093/icb/icr076 
580 Wilson JM, Reimer JP, Allaire D, Lausen CL (2014) Diversity and distribution of bats in the Northwest

$581 \quad$ Territories. Northwestern Naturalist 95 (3):197-218

582 Zuur A, leno EN, Walker N, Saveliev AA, Smith GM (2009) Mixed effects models and extensions in

$583 \quad$ ecology with R. Springer Science \& Business Media, New York

584 


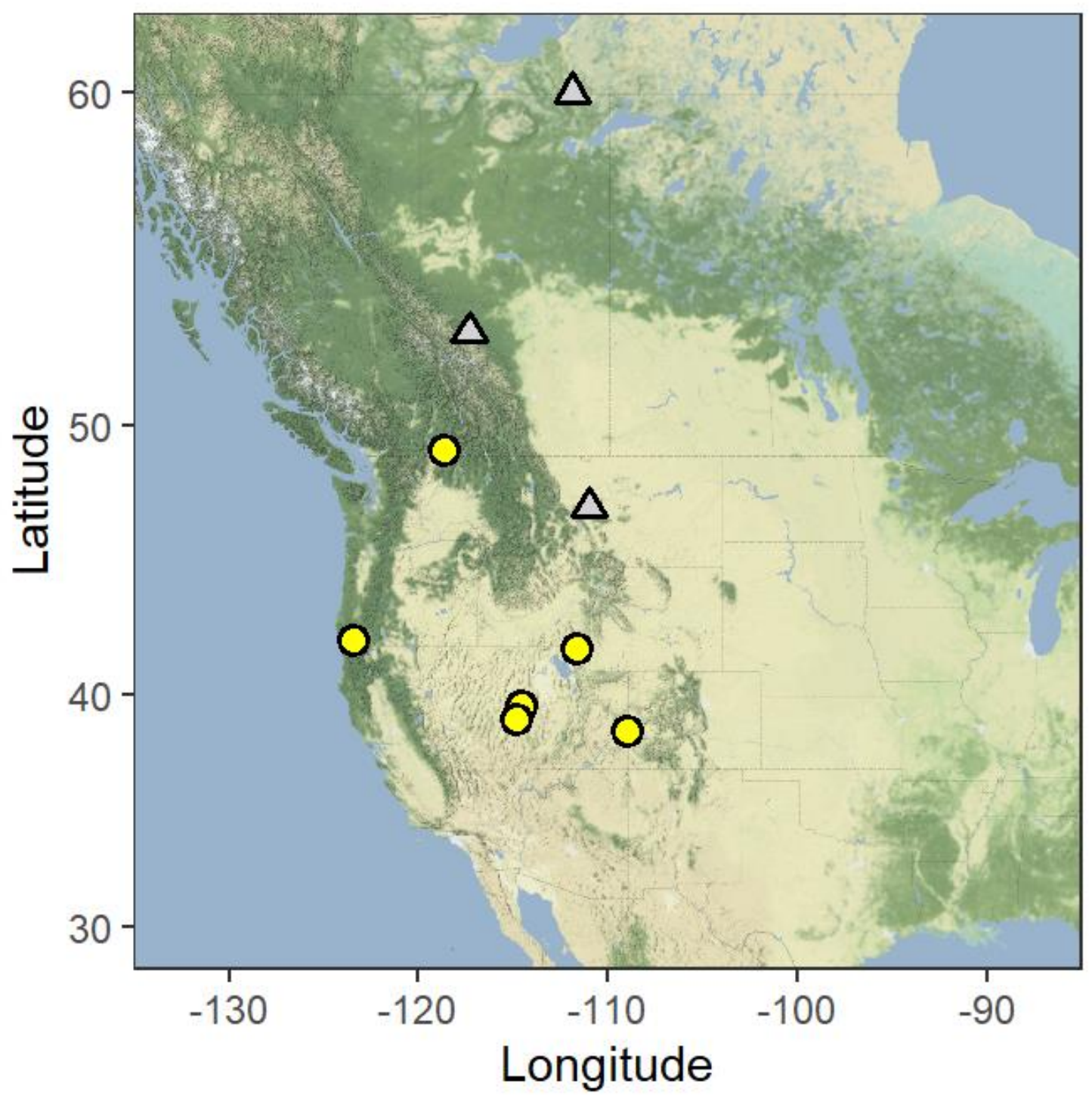

586 Figure 1. We collected data from bats across western North America. Study sites for Myotis lucifugus are indicated in grey triangles and span approximately 1,500 km (approximately 13 degrees of latitude).

588 Study sites for Corynorhinus townsendii are indicated in yellow circles and span approximately 1,200 km 589 east to west, and 1,200 km north to south. For both species, the most northern sites are among the 590 most northerly known hibernacula. Map created with map tiles from Stamen Design (maps.stamen.com; 591 CC BY 3.0). 
(A)

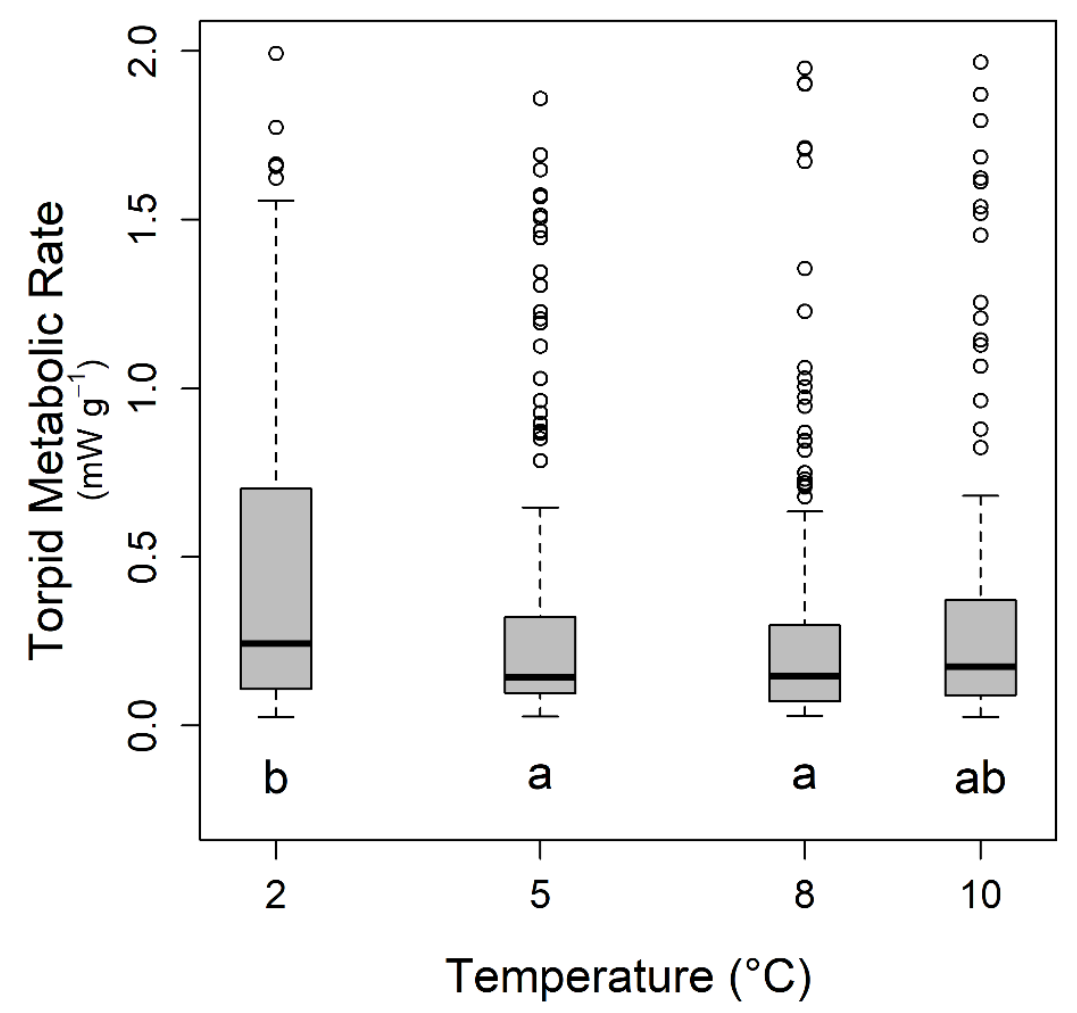

(B)

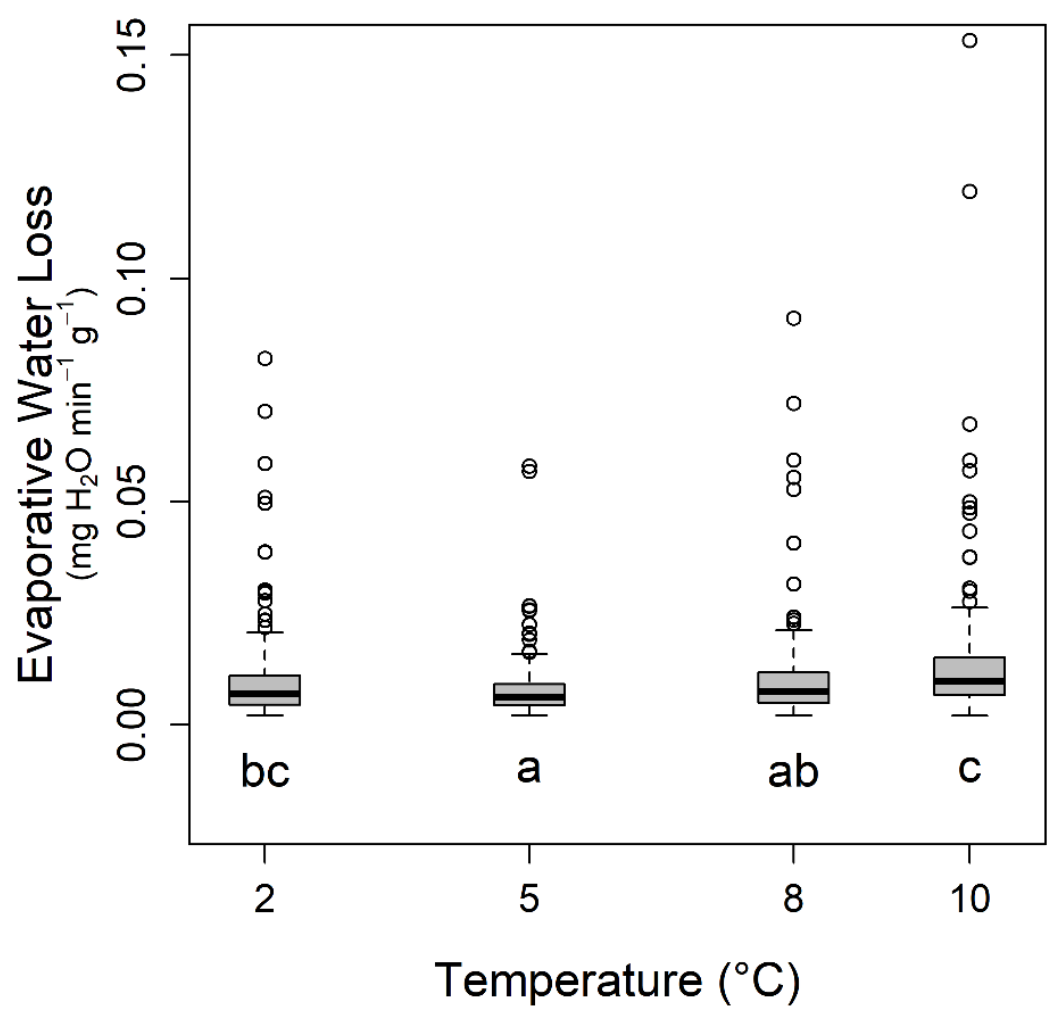

Figure 2. (A) Corynorhinus townsendii $(n=152)$ torpid metabolic rate did not vary across 6 sites, nor did the relationship between site and temperature vary across sites. Minimum metabolic rate was measured between $5-8^{\circ} \mathrm{C}$ and metabolic rate increased at $2^{\circ} \mathrm{C}$. Measurements made during mid-winter were greater than measurements made during pre-hibernation swarming, but both seasons have been combined here for visual simplicity and comparison with M. lucifugus. (B) A similar pattern was observed for evaporative water loss. Minimum evaporative water loss was measured between $5-8^{\circ} \mathrm{C}$. There were generally no differences among sites, except for one pairwise difference between sites in British Columbia and Colorado, but sites have been combined here for visual simplicity. In both plots, temperatures indicated with the same 
letter did not differ. Boxplots indicate median, interquartile range, and outliers (open circles) as determined by standard boxplots in software package $\mathrm{R}$.

(A)

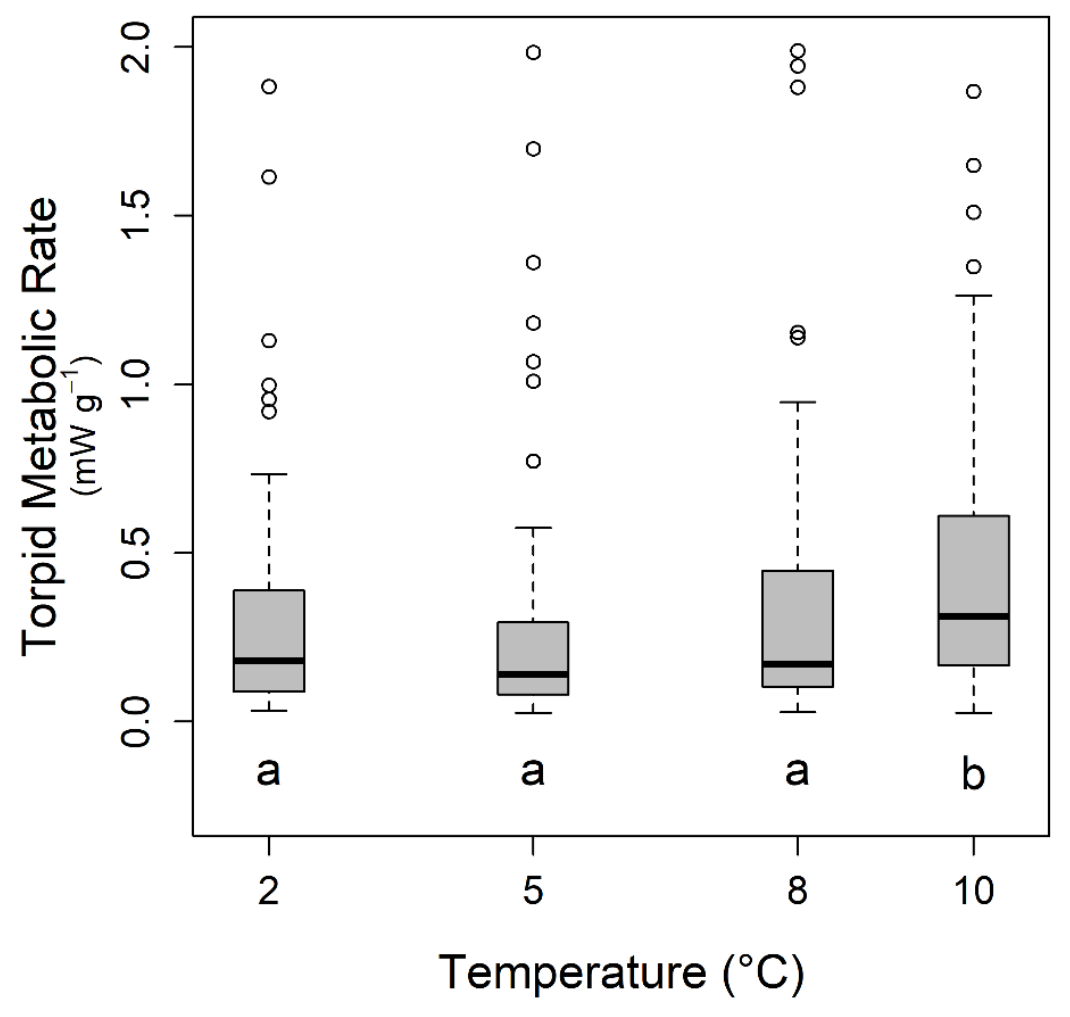

(B)

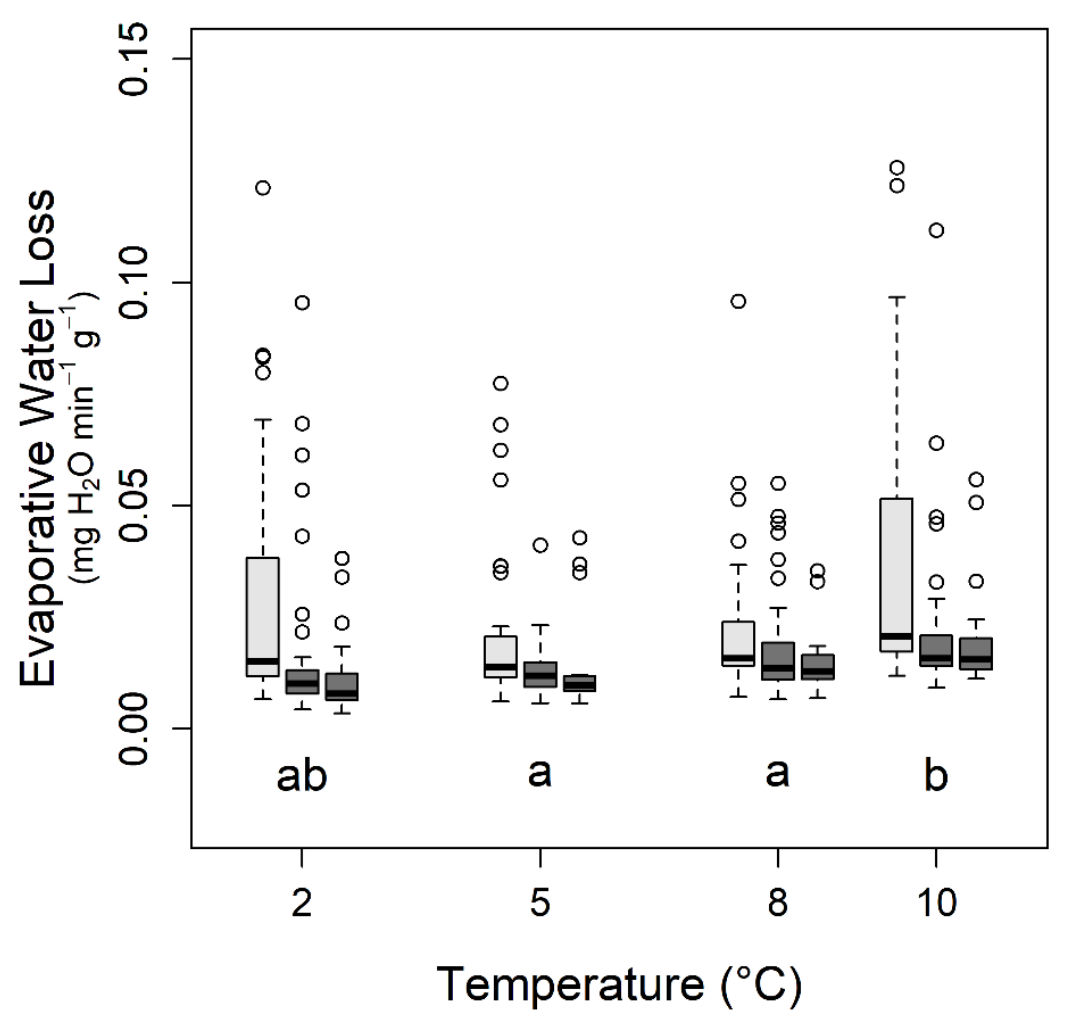

602

Figure 3. (A) Myotis lucifugus ( $\mathrm{n}=99$ ) torpid metabolic rate did not vary across 3 sites, nor did the relationship between site and temperature vary across sites. Minimum metabolic rate was measured between $2-8^{\circ} \mathrm{C}$. (B) Minimum evaporative water loss was measured between $5-8^{\circ} \mathrm{C}$. Evaporative water loss was greater in Montana (light grey) than either Alberta or Northwest Territories (dark grey). In both plots, temperatures indicated with the same letter did not differ. Boxplots indicate median, interquartile range, and outliers (open circles) as determined by standard boxplots in software package $R$. 